\title{
Global Crises: \\ A Network Perspective on the Economic Integration
}

\author{
Ali Leila \\ University of Poitiers
}

\begin{abstract}
This paper borrows from network analysis to study the impact of trade and financial integrations on output drop during the 2008-2009 crisis. Using network analysis, I show that international trade and financial linkages have different effects on economic activity. Relationships involving the trade of goods appear to explain the severity of the crisis to some extent, whereas financial relationships do not. This finding suggests that real shocks that occur through the trade channel cannot be easily and quickly absorbed by connected economies, while financial shocks can be absorbed more easily among partners. The global shift from complex products to safer assets in the wake of the subprime crisis supports this view.
\end{abstract}

- JEL Classification: E65, F10, F30, F36, G15

- Keywords: Contagion, Global Crises, Network Analysis

\section{Introduction}

This paper borrows from network analysis to revisit the question of whether more interconnected countries experienced greater output drop during the 20082009 crisis. Many studies fail to uncover any statistically significant association between the intensity of the economic crisis and linkages with the ground-zero country, the United States. In their search for contagion channels, Rose and Spiegel (2009) show that countries that were more exposed to the United States - i.e. those

\footnotetext{
*Corresponding address: CRIEF-MOFIB, University of Poitiers, 2 Rue Jean Carbonnier Bât A1 (BP 623), 86022 Poitiers Cedex, France. E-mail: Leila.ali@univ-poitiers.fr. Telephone: 33(6) 75766064. (C2011-Center for Economic Integration, Sejong Institution, Sejong University, All Rights Reserved.
} 
that held disproportionate amounts of American securities or depended heavily on exports to the United States - do not seem to have experienced more intense crises. In contrast, Ehrmann et al. (2009) found that financial integration with United States played key role in crisis transmission, but only in equity markets. Others, such as Lane and Milesi-Ferreti (2010), adopted conventional global measures to show that a greater level of financial openness or financial integration is surprisingly associated with weaker slowdown.

One important shortcoming of earlier work is that, thus far, no one has rigorously examined the cascade of linkages between partners. First, by focusing exclusively on the relationship between the ground-zero country and each follower country, previous investigations have neglected the role of linkages between the followers themselves. Second, the link between trade and/or financial integration and vulnerability to crisis is far from clear. All things being equal, two countries with the same level of trade or financial openness may be more or less vulnerable to an international crisis according to their partners' positions and their importance in the trading network.

To fill this gap and investigate all indirect links responsible for crisis transmission, I propose a network-based approach. This framework results in a more complex, but more realistic picture of linkages between countries. I sought to investigate whether the macroeconomic impact of the 2008-2009 crisis depended on all indirect exposures to the ground-zero country. Furthermore, I tested whether establishing relationships with countries characterised by high connectivity with the global network has any impact on the severity of crisis. Then, I investigated whether high global connectivity with the rest of the world goes hand in hand with a stronger crisis.

Related to this paper are studies by Kali and Reyes (2010) or Adarov et al. (2009). Both studies investigate whether integration in the world trade network affected stock market returns during the 1990s. However, Kali and Reyes (2010) mainly implement binary networks and neglect important information provided by valued networks. Adarov et al. (2009) use global trade data to construct a measure of network position, but neglect financial linkages as an alternative measure of connectedness. This paper is different from these two studies in several aspects. First, this paper focuses on the most recent economic turmoil, a point in time where data are assumed to exhibit a strong global pattern. Second, both trade and 
financial network indicators are used as measures of interconnectedness. ${ }^{1}$ Third, weighted network indicators were computed. Taking the weights of ties between countries into account makes it possible to uncover interesting network properties and avoids the arbitrary thresholds required to build binary networks.

Two key concepts of network analysis are utilised to investigate the patterns of integration responsible for interdependencies: distance and centrality measures. The relevance of some network indicators is demonstrated, and I found evidence that trade channels involving goods explained the severity of crisis to some extent, whereas trade in financial assets led to less intense economic disruption. This finding suggests that real shocks that occur via the trade channel can only be propagated among connected economies, while financial shocks can be smoothed among partners, i.e. financial markets are able to absorb shocks more easily. The shift to safer and more transparent assets observed during the last crisis supports the view that, among very well-connected and mature economies, financial markets have mutated and contribute to recovery. These findings also suggest that network indicators should be introduced into country-specific warning systems and can be used to improve the effectiveness of measures directed at stabilising international economic and financial systems.

The remainder of the paper is organized as follows. Section II briefly reviews key network indicators used in this study. Section III describes the main characteristics of international trade and financial networks in 2007, just before the 2008-2009 crisis. Section IV presents the econometric procedure and a discussion of the results. Section V provides concluding remarks and recommendations for future research.

\section{A Network Approach to International Economic Crises}

A network is a set of points called nodes and connections between them are called links. In this paper, nodes depict countries which are connected if they exchange either goods or financial assets. Two networks are of particular interest: a real network that focuses on international trade, and a financial one that is

\footnotetext{
${ }^{1}$ Another branch of the literature has examined the complex trade of goods relationships between countries through the trade channel using input-output linkages across sectors and countries (see Bems, et al. (2010), Eaton et al. (2010) and Benassy-Quere et al. (2009)). This abundant literature does not yet provide a comparable measure for financial relationships. However, homogeneous variables are required to disentangle the effects of each type of channel.
} 
concerned with asset cross-holdings. Trade data were taken from Chelem, a CEPII database, and financial data were extracted from the Coordinated Portfolio Investment Survey (CPIS). ${ }^{2}$ The latter provides the stock of cross-border holdings of securities, broken down by the economy of the country in which the securities issuer resides. ${ }^{3}$

In this weighted network analysis, link weight $\mathrm{w}_{\mathrm{ij}}$ was defined as the volume of trade in goods or assets between any pair of countries $i$ and $j$. More precisely, in the case of the trade network, $\mathrm{w}_{\mathrm{ij}}$ represents the total trade in goods (value of exports plus imports in M\$) between country $i$ and $j$ in 2007. Analogously, in the case of the financial network, $w_{i j}$ represents assets issued by country $\mathrm{j}$ and held by country $i$ and those issued by $i$ and held by $j$ (value in $M \$$ ). As the focus is on whether higher integration with the rest of the world reinforces the crisis phenomenon, networks were treated as undirected, and thereby disregarded the direction of flow. This approach also made it possible to integrate the interpretation of foreign trade and financial multipliers as proposed by Krugman (2008). ${ }^{4}$ All the links reflect quantity and not price.

This paper focuses on whether countries more connected with the ground-zero country and/or with the rest of the world are more prone to severe economic crisis. Thus, to test this hypothesis, key concepts of network analysis were used to investigate the patterns of integration that cause interdependent ripples of initial shocks: distance and centrality measures. All our indicators were computed using free, open-source R software with the Tnet procedures written by Tore Opsahl (2009).

\section{A. Weighted distance index}

This index is based on the general idea that countries today have more links through indirect paths (more vertical productions, greater diversification of portfolios, etc.). Since the direct connection between two countries may not be the most efficient path for evaluating the true level of interdependencies between two countries - due to the weakness of direct linkages -, the distance concept was used.

\footnotetext{
${ }^{2}$ We report for each country of the dataset, how much of total external assets and liabilities is the CPIS measure accounting for in appendix Table A1.

${ }^{3}$ International reserves, direct investments and bank credits are excluded from this survey.

${ }^{4}$ For instance, the ground-zero country affects foreign GDP through its effect on imports via a demand effect. Lower GDP in the ground-zero country leads to lower exports to foreign countries and lower GDP in foreign countries. Likewise, foreign countries affect the ground-zero country in the same way, and so on. This reasoning also applies to financial assets via the wealth or balance sheet effect.
} 
The weighted distance indicators are conditional on linkages with the ground-zero country. The sample here contains n countries, providing n- 1 weighted distance indicators. This index investigates the complex, indirect paths between the groundzero countries and followers. Intuitively, this index is built upon the logic of electrical circuits. As power follows the path of highest intensity, economic shocks are assumed to be transmitted in priority through high intensity linkages. Therefore, on the one hand, I assume that the higher the intensity of linkages between two countries is, i.e. the more frequent exchanges are, the more easily the shock is transmitted between countries. On the other hand, if linkages are tightly knit, the marginal cost of transactions between a pair of countries is lower. Furthermore, with lower costs of transactions between countries, it is easier for investors to modify the composition of their portfolio, find new investment profits and therefore help recovery. Based on Dijkstra's algorithm (1959), the optimal path between the ground-zero country and each follower is the path through which the shock may hit the follower the most severely, and also the one that minimises the marginal cost of going from the ground-zero country to a follower country.

The technical principle is quite intuitive. To determine the optimal path between a pair of countries, Dijkstra's algorithm (1959) inverses the value of weights. In the following example, the direct link between $\mathrm{A}$ and $\mathrm{D}$ is weak, and the distance path of the link is relatively long and probably closer to reality. The measure of distance between the pair of countries (A, D) is obtained through the path $(\mathrm{A}, \mathrm{B}, \mathrm{C}, \mathrm{D})$ and equals 0.783 . The normalised distance is $0.783 \times 3.25=2.54$, which is greater than 1 (3.25 is the average value of links). ${ }^{5}$
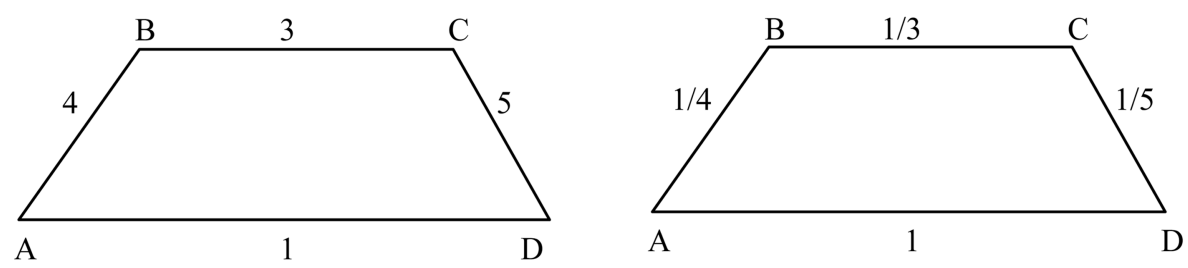

Due to the construction of the index, the lower the distance index is between the ground-zero country and the follower, the more connected the economies are.

\section{B. Centrality indicators}

One measure of centrality that is relevant to this study is the farness index. This

${ }^{5}$ See Tore Opsahl (2009) for details. 
index is not conditioned ${ }^{6}$ upon the ground-zero country. Farness is used to gauge the average proximity of a country with respect to all other countries in terms of trade or financial linkages. To obtain the $\mathrm{n}$ farness index, the distance index between all pairs of countries, and not only with respect to the US economy, was first computed. Then, for each country $i$, a farness score was obtained by summing all the distance indices between $i$ and the rest of the world. The lower the farness index is, the easier it is for country $i$ to access all other countries and the easier it is for all the countries in the world to access country i.

\section{Patterns of Trade and Financial Networks in 2007}

As a first step toward analysing the international trade and financial network indicators, Figure 1. displays the distribution of the index of the normalised distance $^{7}$ from the US market by means of kernel epanechnikov density. In the case of the trade network (Figure 1a.), the distribution highlights the existence of a central group of countries characterised by average connectivity and a peripheral group characterized by low connectivity with United States. Regarding the financial portfolio network (Figure 1b.), a different pattern was observed with one large group characterised by low connectivity with the US market and another large group with higher financial connectivity.

Figure A1. presents countries according to the normalised distance index and to its traditional counterpart, the direct linkages with the US market (exports to and imports from USA of (a) goods and (b) financial assets on the total trade of country i). Patterns observed for the two indices are clearly different. Regarding the international trade network in 2007 and the distance index values, some countries such as Japan, Germany, South Korea or United Kingdom exhibit the strongest linkages with United States. In contrast, according to the direct exposure index, their proximity with the US markets is clearly reduced. Some Eastern European countries such as Russia, Poland, the Czech Republic or Hungary are more linked to the US market than suggested by the direct exposure measure. The picture given by international financial links is more complex. Some developed countries such as United Kingdom, France or Germany are clearly more linked to the US markets

\footnotetext{
${ }^{6}$ In this paper, I use both conditional and unconditional network measures. In a crisis prevention scheme, it is important to show that once a crisis has begun at a specific point in space, some conditional vulnerability indicators can be proposed in addition to unconditional and multilateral network measures. ${ }^{7}$ Both normalised distance and the farness index are expressed in log units due to the large monetary values $(\$)$ of these indicators.
} 
Figure 1. Distribution of distance paths
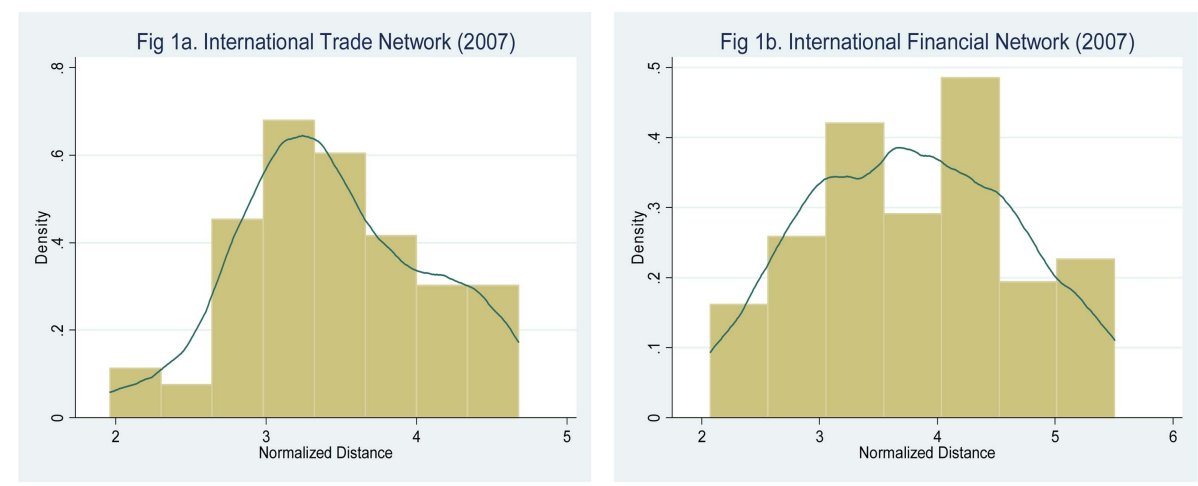

than what is suggested by direct exposure measures. However, Eastern European countries, such as Russia, the Czech Republic, Ukraine, Estonia, Romania, Bulgaria and Latvia, which have been severely hit by the crisis, show low linkages with the United States whatever the measure used and, more especially, the distance index.

As detailed in Section II, another main indicator of networks is the farness index. Figure 2. gives a plot of the distribution of the farness index. Figures $2 \mathrm{a}$. and $2 \mathrm{~b}$ indicate some bimodality. Regarding the trade network, one small group of countries seems to be well connected to the rest of the world (low farness), another smaller group seems to be at the periphery of exchanges and the rest of the world appears to be uniformly distributed. For the financial network, a small group seems to be close to the rest of the world, the rest of the world being uniformly distributed. The scatter plots A2a and A2b show the farness index as well as its traditional counterpart, the share of country $i$ in the total trade of goods or assets. Figures A2. show that the correlation between the two measures is higher than for

Figure 2. Distribution of the farness score
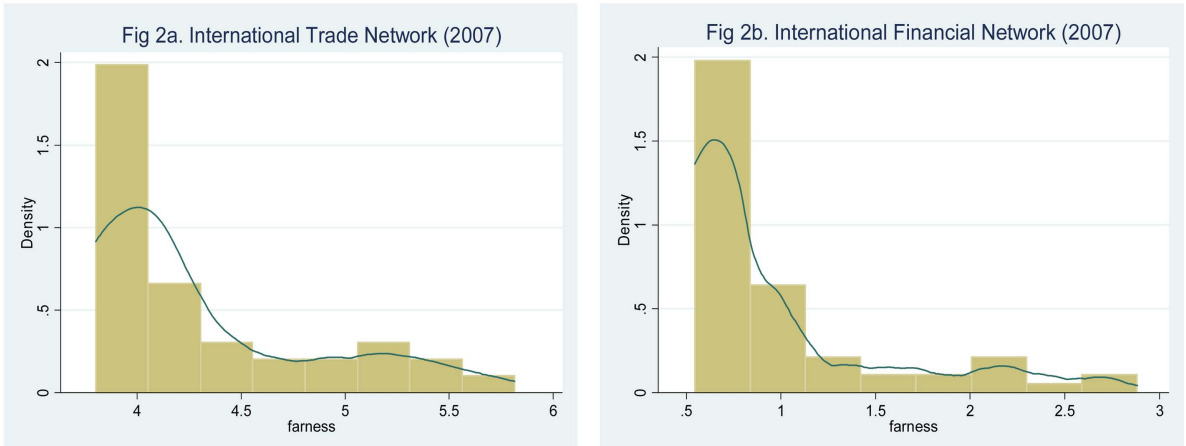
the distance index. Nevertheless, a simple ranking shows that Eastern European countries are among the least connected at the financial level, keeping in mind that financial assets only include equity and bond holdings.

\section{Estimation Approach and Results}

Here, whether and how network indicators may explain output growth after the initial shock erupted in USA is examined. One group of basic specifications are estimated using the following regression equation:

$$
\Delta \hat{Y}_{i}=\alpha+\beta_{1} \times R_{i}+\beta_{2} \times T F_{i}+\beta_{3} \text { Cont }_{i}+\beta_{4} N I_{i}+\varepsilon_{i}
$$

where $\Delta \hat{Y}_{i}$ represents the difference between average GDP growth in 2008 and 2009 and 2004-2007 (in \% points of GDP); $N I_{i}$ represents trade and financial network indicators (US dollars, expressed in log units); Cont $t_{i}$ is a set of traditional variables expressing exposure to the US market. Both direct trade in goods with the USA in share of total trade of country $i$ and direct trade in portfolio assets with USA in share of total trade in portfolio assets of country $i$ are considered. Traditional variables and network indicators were not used together to avoid any correlation bias. Macroeconomic and financial factors were controlled for. Control variables were selected from the empirical literature on the determinants of financial crisis. In particular, $R_{i}$ is a set of domestic variables. It includes the level of GDP per capita (2007, US dollars per capita expressed in log units), the growth rate in domestic credit (in 2007) and the market capitalisation as a share of GDP (04-07). ${ }^{8}$ $T F_{i}$ represents a series of variables related to international exposure as of late 2007, such as the current account as a share of GDP (2007), the ratio reserves on imports (2007, expressed in number of months), the openness ratio (in \% of GDP), the capital openness ratio (Kaopen, a score variable ranging from -1.8 to 2.5 ) and the international financial index as a share of GDP (foreign assets + foreign liabilities) / GDP. ${ }^{9}$ This estimation makes use of data for up to 51 countries, listed in the Appendix (Figure A3.).

\footnotetext{
${ }^{8}$ Due to the high variability of this variable, instead of retaining only one year I chose to use the variable over three years.

${ }^{9}$ The growth rates in GDP have been calculated from the World Economic Outlook of the IMF (October 2009). Most of macroeconomic and financial variables are computed from the World Bank Development Indicators. Note however that the international financial index has been provided by Philip Lane via his web page http://www.philiplane.org/EWN.html; the capital openness ratio developed by Ito and Chinn (2008) has been provided by Hiro Ito "http://www.web.pdx.edu/ ito/" and trade variables are taken from the Chelem database.
} 
A second set of regressions investigates whether the sensitivity of growth to contagion and network indicators depends on the share of international trade and financial markets in the GDP of each country. I tested this hypothesis by introducing interaction terms for the interaction between the contagion and network indicators and trade and financial openness ratios. Regarding the financial openness ratio, I used a measure that takes into account total portfolio assets as provided by the CPIS over GDP (Cpis_GDP) to build interaction variables. To ensure that the interaction term $I_{i}$ does not proxy for one of those variables, all variables were included in the regression separately. Thus, I ran the following regression:

$$
\Delta \hat{Y}_{i}=\alpha+\beta_{1} \times R_{i}+\beta_{2} \times T F_{i}+\beta_{3} \text { Cont }_{i}+\beta_{4} N I_{i}+\beta_{5} I_{i}+\varepsilon_{i}
$$

The results obtained for the first global regression are presented in Table 1. From a qualitative point of view, the results for Model 1 are in agreement with previous findings by Rose and Spiegel (2009). Model 1 indicates that variables involving direct trade and financial exposure with the US market are not significant. ${ }^{10}$ In

Table 1. Estimations from the global OLS model

\begin{tabular}{lccc}
\hline & Model (1) & Model(2) & Model(3) \\
\hline Cred_dom & $0.03^{* *}$ & $0.04^{*}$ & $0.04^{* *}$ \\
Capit & $-0.04^{* *}$ & $-0.04^{* *}$ & $-0.03^{*}$ \\
CA & $-0.21^{* *}$ & $-0.14^{*}$ & -0.05 \\
Resimp & $0.36^{* *}$ & 0.26 & 0.28 \\
GDP capita & $0.86^{* *}$ & 0.79 & $2.26^{* *}$ \\
Open & $0.03^{* *}$ & 0.01 & 0.01 \\
IFI & 0.14 & $0.28^{*}$ & 0.20 \\
Kaopen & -0.83 & -0.58 & $-1.07^{* * *}$ \\
Trshare & 0.08 & & \\
Asshare & -0.05 & & \\
Dist_Tr & & $-2.60^{*}$ & \\
Dist_Ass & & $2.39^{* *}$ & \\
farn_Tr & & & $-2.19^{* *}$ \\
farn_Ass & & & $4.79^{* * *}$ \\
\hline Adjusted R-square & 0.8 & 0.85 & 0.84 \\
Residual Sum of Squares & 412 & 402 & 336 \\
\hline
\end{tabular}

The dependent variable is the difference in average growth output between 2008-2009 and 2004-2007. The number of observations used in estimating models 1 to 3 is $51 .{ }^{* * *},{ }^{* * *}$ : significant at $10 \%, 5 \%$ and $1 \%$, respectively.

\footnotetext{
${ }^{10}$ Both direct exposure of exports and direct exposure as bilateral trade (exports plus imports) were tested. Neither affected the results.
} 
contrast, as can be seen in Model 2, distance variables are significant, but have opposing signs. The magnitudes of the coefficients are quite similar but the financial distance estimates are positive, while the trade distance estimate is negative. Model 2 shows a better goodness-of-fit than Specification 1. Model 3 indicates that farness variables are also significant, with the same sign as the distance coefficients.

In Table 2, the interaction of trade and asset variables with the share of international trade and financial markets in the GDP in each country is investigated. The coefficients for traditional direct linkage variables as well as their interaction terms were included in the regressions but have a non-significant sign. The coefficients of distance are still highly significant and the only interaction coefficients that are significant are those that involve the trade channel. Likewise, the farness score variables are still highly significant and the only interaction

Table 2. Estimations including interaction terms

\begin{tabular}{lccc}
\hline & Model (1') & Model(2') & Model(3') \\
\hline Cred_dom & 0.04 & 0.03 & 0.03 \\
Capit & $-0.03^{* *}$ & -0.00 & -0.01 \\
CA & $-0.19^{* *}$ & -0.02 & -0.01 \\
Resimp & $0.35^{* *}$ & 0.15 & 0.16 \\
GDP capita & $0.96^{* *}$ & $3.06^{* * *}$ & $3.54^{* * *}$ \\
Open & $0.04^{* * *}$ & $-0.26^{* * *}$ & $-0.41^{* * *}$ \\
Cpis_gdp & -1.06 & $2.61^{*}$ & 3.06 \\
Kaopen & $-0.93^{* *}$ & $-1.01^{* * *}$ & $-1.59^{* * *}$ \\
Trshare & 0.15 & & \\
Asshare & -0.09 & & \\
Trshare $\times$ Open & -0.00 & & \\
Asshare $\times$ Cpis_Gdp & 0.06 & $-6.17^{* * *}$ & \\
Dist_Tr & & $3.10^{* * *}$ & \\
Dist_Ass & & $0.09^{* * *}$ & \\
Dist_Tr $\times$ Open & & -0.77 & \\
Dist_Ass $\times$ Cpis_Gdp & & & $-3,03^{* * *}$ \\
Farn_Tr & & & $3.16^{* *}$ \\
Farn_Ass & & & $0.10^{* * *}$ \\
Farn_Tr $\times$ Open & & & -4.92 \\
Farn_Ass $\times$ Cpis_Gdp & 0.79 & 0.84 & 0.87 \\
\hline Adjusted R-square & 402 & & 276 \\
Residual Sum of Squares & & & \\
\hline
\end{tabular}

The dependent variable is the difference in average growth output between 2008-2009 and 2004-2007. The number of observations used in estimating models 1 to 3 is 51 .

$*^{* * *},{ }^{* * *}$ : significant at $10 \%, 5 \%$ and $1 \%$, respectively. 
coefficients that are significant are those that involve the trade channel.

Various tests were conducted to verify the robustness of the model. First, one might argue that the ground-zero country could have been another country, such as the United Kingdom or Germany. To address this issue, the United States was replaced with these two countries as ground-zero countries. As expected, distance indices are no longer significant. Second, the economic significance of the results can be called into question because the sample size is quite small. To address this issue, bootstraps on the regression data set were run. The idea behind bootstrap tests is to generate additional observations, which have the same distribution as the original distribution, via Monte-Carlo type process. This resampling technique did not modify the results from a qualitative point of view. The period for the definition of the endogeneous variable was also modified by using 2008 or 2009 instead of taking the average growth between 2008 and 2009. This modification also had no effect on our findings. Moreover, results remain unchanged after all non-significant coefficients were dropped from the regression (see Table A3 in the Appendix). Finally, I explored two alternative network indicators, the betweenness and the clustering network indicators, whose principles and results are provided in Appendix A2.

Based on the econometric results, several comments can be made. First, in terms of distance coefficients - remembering that a low distance index means high proximity with the United States - it can be inferred that countries that exchange a large amount of goods with the United States through the distance path experience a higher drop in output. In contrast, and more surprisingly, countries that exchange a large amount of assets with the United States experience a lower drop in output. Second, regarding the financial farness score, it can be inferred that the closer the countries from the rest of the world are, the lower the drop in output is during the two-year period (2008-2009). In contrast, regarding the farness score for trade of goods, it can be stated that the closer the countries from the rest of the world are, the stronger the crisis is - remembering that low farness means strong proximity with the rest of the world. Results of regressions including interaction terms suggest that the network index exerts an influence on economic activity well beyond that which a simple share of the trade of goods or portfolio assets have on the GDP. This disproportional effect is in line with the international multiplier concept proposed by Krugman (2008).

The impacts of trade and financial linkages appear to have opposite effects. In areas that are financially close to the ground-zero country, shocks may be 
smoothed. However in trade relationships, it may more difficult to change partners and shocks can thereby only be passed on. The transmission of shocks through vertical production linkages may be high. As shown by Levchanko et al. (2010), when there is a drop in final output, the demand for intermediate input will suffer, leading to a proportional drop in trade flow. Di Giovanni and Levchenko (2010) demonstrate that greater sector-level vertical linkages play a role in the transmission of economic shocks between countries.

From the financial viewpoint, specifically in terms of portfolio investments, markets strongly connected with the United States and the rest of the world have the capacity to react quickly. Undoubtedly, financial factors are part of the initial step at the root of the spread of the crisis through, among other things, margin call and balance sheet effects of leveraged common investors, wealth losses, etc. However, considering the macroeconomic impact of the crisis over a two-year period after the beginning of disturbances in the United States, countries that were financially better integrated suffered less and found new opportunities. The flight to quality during the last crisis supports this view. As turbulence related to the US subprime crisis heightened, investors moved away from complex, structured products to safer and more transparent assets. Positions were shifted to invest in the safest and most liquid of assets: treasury bonds. The latter movement was reflected in a significant increase in the prices of US treasury securities. This may have helped official state borrowing. Furthermore, in well-connected mature economies, investors may have channelled investment away from unproductive residential construction into more productive areas that contributed to recovery. Mergers among financial institutions are another illustration of their ability to react to crises.

\section{Conclusion and Outlook for Future Research}

The recent worldwide financial crisis of 2008-2009 that first erupted in USA affected some countries while others seem to have been less influenced. Building upon network tools, I analysed to what extent complex trade and financial linkages between countries contributed to this pattern.

Here, it was demonstrated that measuring the role of trade or financial linkages with the ground-zero country by using only direct and bilateral indicators may lead to errors. Indirect paths of distance are probably closer to the reality of complex linkages between countries than traditional bilateral exposure variables. Likewise, the farness index proposes an alternative to the traditional openness ratio for trade 
or finance. Network indicators take the position of countries in the network into account, as well as the position of the partners in the networks. Surprisingly, it was found that trade integration actually contributes to the severity of the crisis, while financial integration can help countries recover. Many economists recognise that it is not clear on ex-ante basis whether a larger international balance sheet should be associated with a greater or lesser exposure to the global crisis. Paradoxically, this paper suggests that a larger international balance sheet may provide valuable diversification in the event of instability in the financial system. A country that is financially well-integrated is less exposed to decreases in domestic asset values to the extent that it has issued claims on domestic assets of foreign investors. This network approach may be useful for assessing appropriate thresholds of intervention in each country included in the dataset. Nevertheless, the results reveal some limitations. To overcome these caveats, some directions for future research are proposed.

First, policymakers and international financial institutions often search for indications of when and how pre-emptive measures can mitigate or even prevent financial turmoil. Obviously, financial policies played a certain role in shielding economies and rescuing financial systems. The next step will be to directly address this question. Second, this investigation was mainly macroeconomic. Consequently, some properties of networks are not well represented by our model. Future research will need to examine linkages between financial institutions and even between firms. The specific nature of networks inside a country may explain the resilience or the vulnerability of some economies to financial shocks. Finally, to take into account the difference between financial time and real time, a dynamic model could be used. Recent advances in dynamic network modelling may prove useful.

\section{Acknowledgements}

I thank Christian Aubin, Jean-Marc Bascans, Andre Cartapanis, Olivier BoubaOlga, Daniel Goyeau, Jacques Leonard, Tore Opsahl, Cornel Oros, Francesco Ricci and Ursula Vogel for their helpful comments on a preliminary version of this paper.

Received 24 August 2010, Revised 24 January 2011, Accepted 20 April 2011 


\section{References}

Adarov, A., Kali, R., Reyes, J. (2009), Stock Market Synchronicity and the Global Trade Network: A Random-Walk Approach, Mimeo.

Barrat, A., Barthelemy, M., Pastor-Satorras, R., Vespignani, A. (2004), The Architecture of Complex Weighted Networks, Proceedings of the National Academy of Sciences, 101(11), 3747-3752.

Bems R.C. Johnson, and K.-M. Yi. (2010), Demand Spillovers and the Collapse of Trade in the Global Recession, IMF Economic Review, 52(2).

Benassy-Quere, A., Y. Decreux, L. Fontagne, and D. Khoudour-Casteras. (2009), Economic Crisis and Global Supply Chains, CEPII Document de Travail, \# 2009-15.

Brandes, U. (2001), A faster Algorithm for Betweenness Centrality, Journal of Mathematical Sociology, 25(2), 163-177.

Di Giovanni, J., Levchenko, A. (2010), Putting the Parts Together: Trade, Vertical Linkages, and Business Cycle Comovement, American Economic Journal: Macroeconomics, 2(2), 95-104.

Dijkstra, E.W. (1959) A Note on Two Problems in Connection with Graphs, Numerische Mathematik, $\mathrm{N}^{\mathrm{o}} 1,269-271$.

Eaton, J., S. Kortum, B. Neiman, and J. Romalis (2010), Trade and the Great Recession, Unpublished Manuscript, University of Chicago.

Ehrman, M., Fratzscher, M. (2009), Global Financial Transmission of Monetary Policy Shocks, Oxford Bulletin of Economics and Statistics, 71(6), 739-760.

Freeman, L.C. (1979), Centrality in Social Networks: Conceptual Clarification, Social Networks, 1(3), 215-239.

Ito, H. and Chinn, M. (2008), A New Measure of Financial Openness, Journal of Comparative Policy Analysis, 10(3), 309-322.

Kali, R., Reyes, J. (2010), Financial Contagion on the International Trade Network, Forthcoming in Economic Enquiry.

Krugman, P. (2008), The International Financial Multiplier, Mimeo.

Lane, P., Milesi-Ferreti, G. (2010), The Cross-Country Incidence of the Global Crisis, Mimeo.

Levchenko, A., Logan, L., Tesar, L. (2010), The Collapse of International Trade during the 2008-2009 Crisis: In Search of the Smoking Gun, NBER Working Paper, $\mathrm{N}^{\mathrm{o}} 16006$, Forthcoming in IMF Economic Review.

Opsahl, T. (2009), Structure and Evolution of Weighted Networks, University of London, Queen Mary College, 104-122.

Rose, A., Spiegel, M. (2009), Cross-Country Causes and Consequences of the 2008 Crisis: International Linkages and American Exposure, NBER Working paper, $\mathrm{N}^{\circ}$ 15358. 


\section{Appendix}

Table A1. Share of the CPIS measure on total external assets and liabilities* (in \%)

\begin{tabular}{|c|c|c|c|}
\hline Argentina & 15,29 & Kuwait & 6,88 \\
\hline Australia & 44,40 & Latvia & 2,94 \\
\hline Austria & 36,19 & Lebanon & 4,41 \\
\hline Bahrain & 11,34 & Luxembourg & 40,51 \\
\hline Belgium & 25,57 & Malaysia & 27,17 \\
\hline Brazil & 28,41 & Malta & 16,33 \\
\hline Bulgaria & 5,56 & Mexico & 21,79 \\
\hline Canada & 50,98 & Netherlands & 40,72 \\
\hline Chile & 32,31 & New Zealand & 20,91 \\
\hline Colombia & 15,62 & Norway & 43,24 \\
\hline Costa Rica & 7,09 & Pakistan & 4,73 \\
\hline Cyprus & 29,78 & Panama & 70,10 \\
\hline Czech Republic & 19,06 & Philippines & 23,90 \\
\hline Denmark & 37,81 & Poland & 20,28 \\
\hline Egypt & 16,55 & Portugal & 38,04 \\
\hline Estonia & 17,36 & Romania & 4,69 \\
\hline Finland & 47,79 & Russia & 10,61 \\
\hline France & 34,37 & Singapore & 27,22 \\
\hline Germany & 39,08 & Slovak Republic & 11,78 \\
\hline Greece & 47,07 & South Africa & 36,53 \\
\hline Hong Kong & 18,92 & Spain & 37,48 \\
\hline Hungary & 14,32 & Sweden & 40,60 \\
\hline Iceland & 30,35 & Switzerland & 28,07 \\
\hline India & 38,03 & Thailand & 18,36 \\
\hline Indonesia & 16,32 & Turkey & 14,73 \\
\hline Ireland & 46,67 & Ukraine & 6,28 \\
\hline Israel & 27,40 & United Kingdom & 25,16 \\
\hline Italy & 44,98 & United States & 32,99 \\
\hline Japan & 44,10 & Uruguay & 20,09 \\
\hline Kazakhstan & 15,48 & $\begin{array}{l}\text { Venezuela, Rep. } \\
\text { Bol. }\end{array}$ & 10,46 \\
\hline Korea & 35,34 & & \\
\hline
\end{tabular}

*This proportion represents the weight the CPIS measure represents has on total international assets and liabilities. Total assets and liabilities were extracted from the Philip Lane database.

\section{A2. Alternative network indicators: betweenness and clustering indices}

Principle of the betweenness index

The betweenness index measures the relevance of a particular country to the 
overall trade or financial network. In a network, certain countries occupy advantageous positions, whereas others rely on these countries for exchange (assets, goods or information). The extent to which a country is part of the transactions can be studied using Freeman's (1979) betweenness index for binary links. In this context of weighted networks, to calculate a betweenness index, Brandes' (2001) algorithm was used. This algorithm is a generalisation of the Freeman index. All the distance paths between pairs of countries are evaluated first. Then, the number of times that country $i$ is on the path is estimated. The higher the index, the more central the country is for the trade or financial network. The reasoning behind its computation is as follows. Let $d(A, B)$ denote the distance between countries $A$ and $B$, i.e. the minimum length of any paths connecting $A$ to $B$. Let $\sigma_{A B}=\sigma_{B A}$ denote the number of shortest paths from $A$ and $B$. Let $\sigma_{A B}(v)$ denote the number of shortest paths from $A$ to $B$ that some country $v$ lies on. A country $v$ lies on the shortest path (the more efficient) between countries $A$ and $B$, if and only if $d(A, B)=d(A, v)+d(v, B)$. Given pairwise distances and shortest path counts, the pair-dependency $\delta_{A B}(v)=\frac{\sigma_{A B}(v)}{\sigma_{A B}}$ of a pair $A$ and $B$ on an
intermediary is given by:

$$
\sigma_{A B}(v)=\left\{\begin{array}{l}
0 \text { if } d_{(A, B)}<d_{G(A, v)}+d_{G(v, B)} \\
1 \text { otherwise }
\end{array}\right.
$$

To obtain the betweenness centrality index of a country, the sum of the pairdependencies of all pairs on that country was taken:

$$
C_{(v)}=\sum_{A \neq v \neq B} \delta_{A B}(v)
$$

\section{Principles of the weighted local clustering coefficient}

It is examined here the role of clustering of countries confronting the crisis: does establishing relationships with partners that are themselves partners constitute a protection or not? The weighted local clustering coefficient is also considered as an unconditional indicator. It measures the extent to which partners of country $i$ are inter-connected with each other. Here, the algorithm developed by Barrat et al. (2004) was used. Barrat et al. (2004) proposes a generalisation of the local clustering coefficient to weighted networks by using the weights explicitly. To compute the weighted local clustering coefficient, Barrat et al. (2004) assigned a triplet value to each triplet in the network based on the arithmetic mean. Then, for each country, they summed the value of the closed triplets that were centred on the 
country and divided it by the total value of all triplets centred on the country. Local weighted clustering coefficient is formally defined as follows:

$$
C^{W}=\frac{\sum_{j h}\left(w_{i j}+w_{i h}\right) / 2 \times a_{i j} \times a_{i h} \times a_{j h}}{\sum_{j h}\left(w_{i j}+w_{i h}\right) / 2 a_{i j} \times a_{i h}}
$$

With the adjacency matrix $a$ whose entries $\mathrm{a}_{\mathrm{ij}}$ are 1 if the node $i$ is connected with node $j$ and 0 otherwise.

Table A2. Estimations with alternative network indicators

\begin{tabular}{lcc}
\hline & Model(4) & Model(5) \\
\hline Cred_dom & 0.03 & 0.03 \\
Capit & $-0.04^{* *}$ & $-0.04^{* *}$ \\
CA & $-0.22^{* * *}$ & $-0.21^{* * *}$ \\
Resimp & 0.32 & $0.32^{*}$ \\
GDP capita & 1.18 & $0.80^{* *}$ \\
Open & $0.03^{* *}$ & $0.03^{* * *}$ \\
IFI & $0.14^{*}$ & 0.17 \\
Kaopen & -0.82 & $-0.77^{* *}$ \\
Clust_Tr & 0.29 & \\
Clust_Ass & -0.31 & 0.05 \\
Betw_Tr & & -0.06 \\
Betw_Ass & & 0.78 \\
\hline Adjusted R-square & 0.79 & 436 \\
Residual Sum of Squares & 429 & \\
\hline
\end{tabular}

The dependent variable is the difference in average growth output between 2008-2009 and 2004-2007.

Table A3. Estimations without insignificant variables

\begin{tabular}{lcc}
\hline & Model (1') & Model(2') \\
\hline GDP capita & $3.65^{* * *}$ & $4.01^{* * *}$ \\
Open & $0.31^{* * *}$ & $-0.32^{* * *}$ \\
Cpis_gdp & $0.71^{* * *}$ & $0.38^{*}$ \\
Kaopen & $-1.20^{* * *}$ & $-1.78^{* * *}$ \\
Dist_Tr & $-7.33^{* * *}$ & \\
Dist_Ass & $3.77^{* * *}$ & \\
Dist_Tr $\times$ Open & $0.10^{* * *}$ & $-3.49^{* * *}$ \\
Farn_Tr & & $4.29^{* * *}$ \\
Farn_Ass & & $0.09^{* * *}$ \\
Farn_Tr $\times$ Open & & 0.86 \\
\hline Adjusted R-square & 0.85 & 311 \\
Residual Sum of Squares & 343 & $2008-2009$
\end{tabular}

The dependent variable is the difference in average growth output between 2008-2009 and 2004-2007. 
Figure A1a. Trade distance indices with respect to the USA versus direct trade in goods with USA (2007).

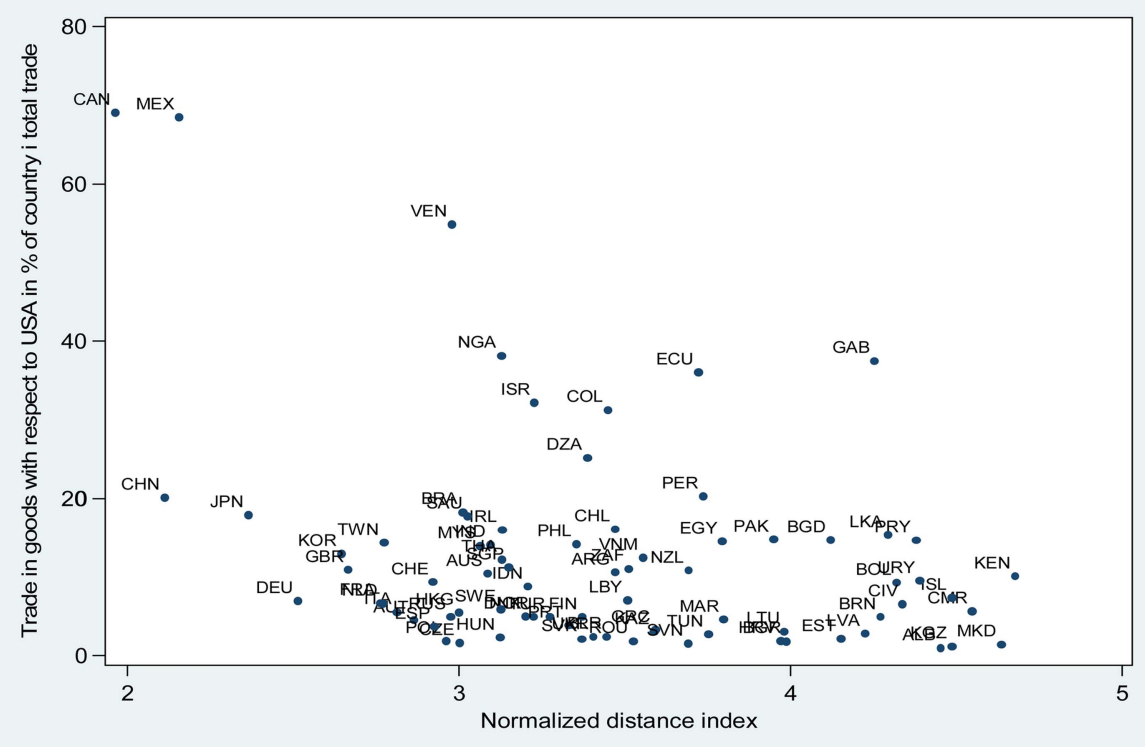

Figure A1b. Financial distance indices with respect to the USA versus direct trade in assets with USA (2007).

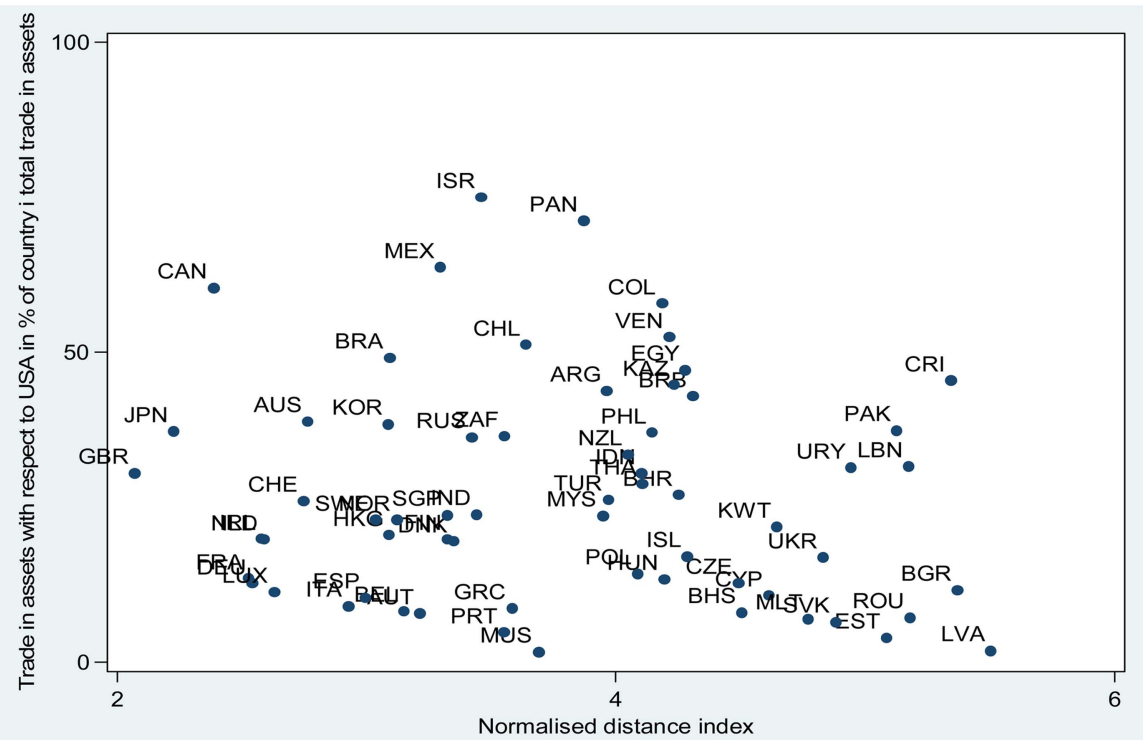


Global Crises: A Network Perspective on the Economic Integration

215

Figure ALa. 'Trade in goods harness indices versus share of country 1 in total trade.

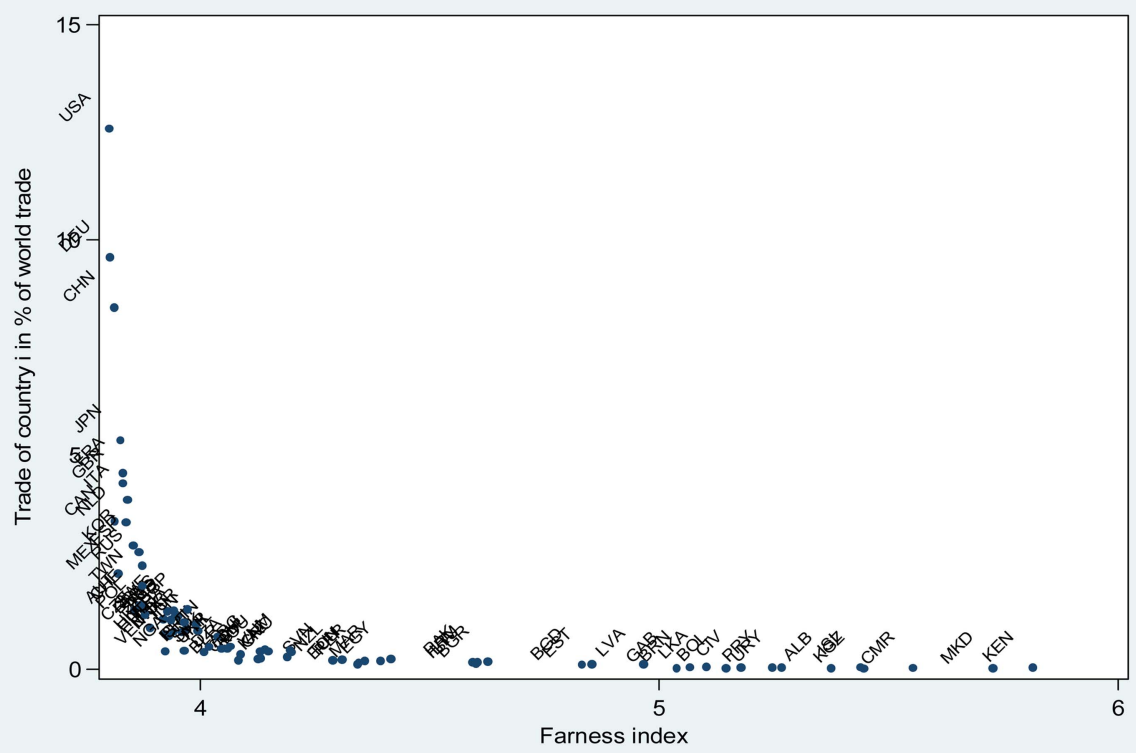

Figure A2b. Trade in assets farness indices versus share of country i in total trade (2007).

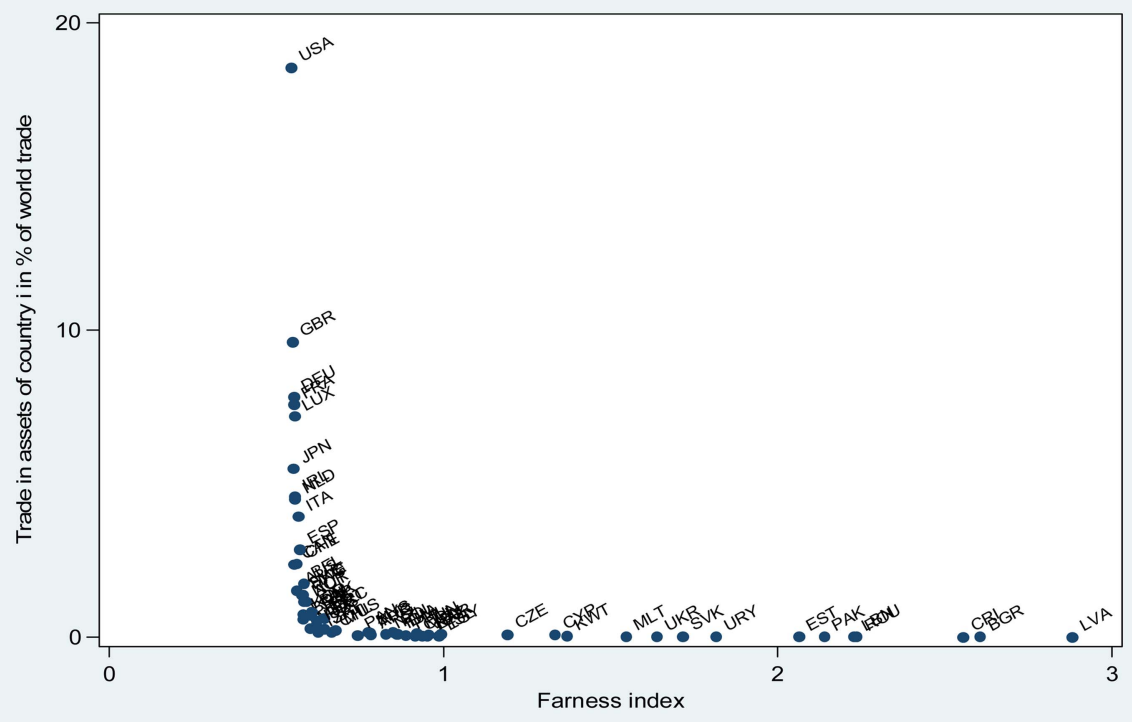


Figure A3.

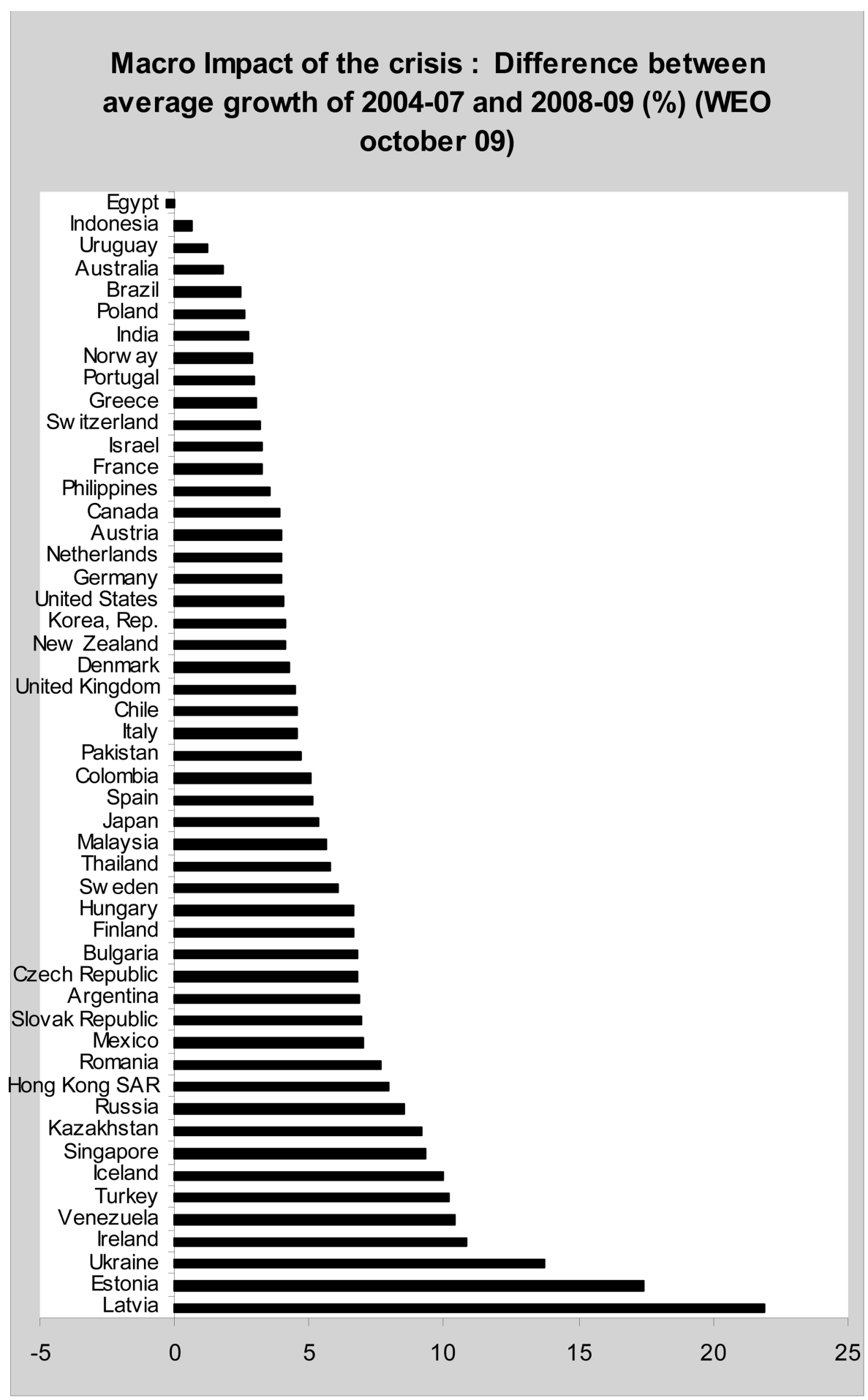

